\title{
Research
}

\section{Difficulties in differential diagnosis of COPD and asthma in primary care}

\begin{abstract}
Background

Chronic obstructive pulmonary disease (COPD) and asthma treatment must be based on appropriate diagnosis. However, patients receiving inhaled therapy in primary care may not be accurately diagnosed according to current guidelines.

\section{Aim}

To analyse the characteristics of patients treated with inhaled medication, the concordance of tools for differential diagnosis, and the adequacy of prescription of inhaled corticosteroids (ICs) in primary care.

\section{Design and setting}

Cross-sectional, multicentre, non-interventional study conducted in 10 primary care centres in Barcelona, Spain.

Method

Patients with chronic respiratory disease, aged $>40$ years were treated with ICs. They provided sociodemographic and clinical information and performed forced spirometry with a bronchodilator test (BDT). The diagnostic accuracy of asthma and COPD diagnoses were tested using two differential diagnosis questionnaires.

\section{Results}

A total of 328 patients were initially classified as having COPD (64.8\%), asthma (15.4\%), or indeterminate (19.8\%) by their GPs. After spirometry, $40 \%$ of patients had moderate-severe airflow obstruction according to the GOLD classification; mean reversibility of forced expiratory volume in 1 second (FEV1) was $8.4 \%$ : $18.6 \%$ had a positive BDT; and $39.8 \%$ had postbronchodilator FEV1/forced vital capacity $>0.7$. Concordance of the differential diagnosis tools was moderate (clinical diagnosis versus spirometry and between the two questionnaires), low (clinical diagnosis versus questionnaires), and very low (spirometry versus differential diagnosis). Of the patients diagnosed with COPD, $71.4 \%$ were treated with ICs, and $12 \%$ of those classified as having asthma were not receiving ICs.
\end{abstract}

\section{Conclusion}

Most patients can be classified as having COPD or asthma by primary care physicians. The use of the two questionnaires did not provide a better differential diagnostic compared with symptoms and spirometry with a BDT. Misdiagnosis may lead to inadequate treatment.

\section{Keywords}

asthma; chronic obstructive pulmonary disease inhaled corticosteroids; primary care; diagnosis.

\section{INTRODUCTION}

Chronic obstructive pulmonary disease (COPD) is a slow, progressive disease characterised by poorly reversible airflow limitation. The prevalence of COPD in Spain currently extends to $10.2 \%$ of the adult population, reaching $35 \%$ in males aged $>70$ years. ${ }^{1}$ In spite of its prevalence, this condition is highly underdiagnosed. ${ }^{1}$ In addition, misdiagnosis between COPD and other lung diseases, especially asthma, appears to be an important clinical problem. $^{2}$

In most countries, most patients with chronic respiratory diseases are managed by primary care physicians. In the last few years, clinical guidelines, such as the Global initiative for chronic Obstructive Lung Disease (GOLD) ${ }^{3}$ and the Global Initiative For Asthma ${ }^{4}$ have been developed for the management of COPD and asthma respectively. However, guidelines have been difficult to implement in Spain, particularly in the primary care setting: $:^{5}$ perhaps because there is a greater focus on secondary than on primary care and these respiratory conditions are perceived as complex, or because some patients in primary care may present with undifferentiated symptoms. ${ }^{6}$

Most respiratory guidelines agree that spirometry should be the basis for the diagnosis of COPD, 3,6,7 and differential diagnosis of asthma and COPD is based on a combination of history, physical

M Miravitlles, MD pulmonologist, Institut d'Investigacions Biomèdiques August Pi i Sunyer (IDIBAPS), Ciber de Enfermedades Respiratorias (CIBERES), Hospital Clinic, Barcelona, Spain. I Andreu, MD, primary care physician; Y Romero, MD, primary care physician, Centre d'Atenció Primària (CAP) Numancia. Barcelona, Spain. S Sitjar, MD, primary care physician, CAP Les Corts, Barcelona, Spain. A Altés, MD, primary care physician, CAP Sans, Barcelona, Spain. E Anton, MD, pulmonologist, Medical Department, Pfizer, Madrid, Spain. examination, and confirmation of the presence of airflow obstruction (defined as post-bronchodilator forced expiratory volume in 1 second/forced vital capacity [FEV1/FVC] <0.7) using spirometry. In the primary care setting, access to spirometry is often limited by time constraints and difficulty in interpretation, leading to underuse. ${ }^{8-10}$ Symptom-based questionnaires could be used to help differentiate between COPD and asthma among individuals thought to have obstructive lung disease. Used in conjunction with spirometry, these tools may enhance the diagnostic accuracy of obstructive lung disease., ${ }^{2,1}$

Differentiating between asthma and COPD is essential for determining appropriate drug therapy. For the treatment of asthma, inhaled corticosteroids (ICs) are the most effective controller medications currently available. ${ }^{4}$ On the other hand, the basis for treatment in COPD is an inhaled (long-acting) bronchodilator, while ICs are usually recommended in patients with severe disease (FEV1 $<50 \%$ ) and in those with a history of recurrent exacerbations., 3,6,7

Apart from the poor response to ICs in COPD, the risk of inappropriate use should also be considered. IC therapy has adverse effects, including dysphonia, skin bruising. oral candidiasis, and diminished bone density. In addition, recent studies have demonstrated a higher risk of pneumonia associated with the use of ICs in patients with COPD. ${ }^{12,13}$ In this context, a recent

\section{Address for correspondence}

Marc Miravitlles, Servei de Pneumologia. Hospital Clínic, Villarroel 170. 08036 Barcelona, Spain.

E-mail: marcmasepar.es

Submitted: 6 October 2011; Editor's response: 1 November 2011; final acceptance: 15 November 2011.

\section{CBritish Journal of General Practice}

This is the full-length article (published online 30 Jan 2012) of an abridged version published in print. Cite this article as: Br J Gen Pract 2012; DOI: 10.3399/bjgp12X625111 


\section{How this fits in}

Asthma and chronic obstructive pulmonary disease (COPD) are not always easy to differentiate. Results of this study show that most patients can be readily classified by primary care physicians as having asthma or COPD based on clinical and spirometric findings, but there are difficulties in classifying up to $19.8 \%$ of patients with obstructive respiratory symptoms. Short differential diagnosis questionnaires provided scarce additional information and concordance between them for the differential diagnosis of COPD and asthma was weak.

meta-analysis ${ }^{14}$ concluded that the use of ICs in patients with stable COPD does not reduce mortality and significantly increases the incidence of pneumonia. Conversely, the use of long-acting beta agonists (LABAs) as monotherapy for asthma is not recommended for safety reasons.

Taking all of this into account, it is important to increase the awareness of differences between the two diseases to promote optimal treatment. However, most patients receiving inhaled therapy in primary care are not accurately diagnosed according to current guidelines for COPD and asthma. ${ }^{2,15}$

The aim of this study was to analyse the characteristics of patients treated with inhaled medication in primary care, to investigate the concordance of different tools that can be used for the differential diagnosis of COPD and asthma, and to ascertain the adequacy of IC prescription in this population.

\section{METHOD}

This was a cross-sectional, multicentre, non-interventional study conducted in 10 primary care centres in Barcelona, Spain from March 2009 to September 2009. Participants were unselected, consecutive patients, aged $>40$ years, with a history of chronic respiratory symptoms lexertional dyspnoea, cough and/or sputum production) and prior treatment with inhaled medications cared for in primary care settings. Exclusion criteria were any condition preventing the performance of spirometry at the time of the study and serious physical or mental impairment that would make fulfillment of the quality of life survey impossible. Respiratory and concomitant medication was allowed as required by usual clinical practice.

In a single visit, patients provided information about sociodemographic and clinical data and performed a forced spirometry with bronchodilator test in accordance with the American Thoracic Society guidelines. ${ }^{16}$ A positive bronchodilator response was defined as an increase in FEV1 of $200 \mathrm{ml}$ and $12 \%$ or greater, compared with baseline, 15 minutes after inhalation of two puffs of salbutamol. Investigators then completed two questionnaires for differential diagnosis between asthma and COPD: the first was developed by Tinkelman et $a^{11}$ and is composed of 13 items including, among others, questions about smoking habits and respiratory symptoms; the second, developed by Beeh et $a{ }_{1},{ }^{17}$ is based on age at onset of symptoms, smoking history, atopy, and cough quality. Body mass index was calculated based on measures obtained before spirometry.

The Charlson Index ${ }^{18}$ was used to quantify comorbidity. Patients completed the Spanish version of the EuroQoL-5D, ${ }^{19}$ which comprises a five-item questionnaire, to evaluate health status (mobility, self-care, usual activities, pain, and anxiety); the EuroQoL-5D visual analogue scale graded from 0 (the worst imaginable health state) to 100 (the best imaginable health state); and the Medical Research Council dyspnoea scale ${ }^{20}$ which establishes five degrees of perceived respiratory disability, ranging from troubled by breathlessness only on strenuous exercise (grade 1) to too breathless to leave the house, or breathless when dressing or undressing (grade 5).

Four different diagnostic classifications between asthma and COPD were established:

- Clinical diagnosis. Physicians classified patients as having COPD, asthma, or indeterminate, according to medical history, clinical examination, and their interpretation of spirometry.

- Classification using the Tinkelman et al questionnaire for differentiating COPD and asthma.

- Classification according to the Beeh et al questionnaire for the differentiation of asthma and COPD.

- Classification according to clinical history and spirometry with bronchodilator test as described by Price et a ${ }^{21}$ (Table 1).

\section{Statistical methodology}

Sample size was predetermined to be 340 patients, assuming an expected prevalence of COPD of $33 \%$ among patients aged $>40$ years, with inhaled medication, 


\section{Table 1. Diagnostic categories based on spirometry with} bronchodilator test

\begin{tabular}{ll} 
Study diagnosis & Criteria \\
\hline COPD without reversible component & Postbronchodilator FEV1/FVC $<0.70$ \\
& Reversibility $<200 \mathrm{ml}$ or $<12 \%$ of baseline FEV1 \\
\hline COPD with reversible component & Postbronchodilator FEV1/FVC $<0.70$ \\
& Reversibility $\geq 200 \mathrm{ml}$ and $\geq 12 \%$ of baseline FEV1 \\
\hline Asthma & Postbronchodilator FEV1/FVC $\geq 0.70$ \\
& Reversibility $\geq 200 \mathrm{ml}$ and $\geq 12 \%$ of baseline FEV1 \\
\hline Probable asthma & Postbronchodilator FEV1/FVC $\geq 0.70$ \\
& Reversibility $<200 \mathrm{ml}$ or $<12 \%$ of baseline FEV1 and \\
& Prior diagnosis of asthma or patient is taking \\
& corticosteroids on a chronic basis \\
\hline Probably normal & Postbronchodilator FEV1/FVC $\geq 0.70$ \\
& Reversibility $<200 \mathrm{ml}$ or $<12 \%$ of baseline FEV1 and \\
& Does not fulfil criteria for probable asthma \\
\hline COPD = chronic obstructive pulmonary disease. FEV1/FVC $=$ forced expiratory volume in 1 second/forced \\
vital capacity.
\end{tabular}

attending primary care centres, by using the normal distribution for large samples with a confidence level of $95 \%$ and a two-tail comparison test to estimate the prevalence of patients with a proper diagnosis of COPD with an error of precision $<5 \%$. For the main objective, a descriptive analysis of frequencies was employed by means of a prevalence estimate and the corresponding 95\% confidence intervals (Cls). Quantitative variables were compared between groups using analysis of variance and the qualitative variables using the $\chi^{2}$ test. To assess the correlation between the different criteria and methods of diagnosis the power of concordance was determined using the Cohen's Kappa index, considering the following levels of concordance: $<0.20=$ very low; 0.21 to $0.40=$ low; 0.41 to $0.60=$ moderate; 0.61 to $0.80=$ good and 0.81 to 1 = very good. SPSS (version 16.0) was used for statistical analysis.

\section{RESULTS}

\section{Patients characteristics}

A total of 29 primary care physicians included 328 patients, four of whom did not fulfil the inclusion and exclusion criteria and were excluded. From the clinical diagnosis based on physicians' criteria, participants were classified into three groups: COPD (64.8\%), asthma (15.4\%), and indeterminate (19.8\%). Their characteristics are shown in Table 2. Mean FEV1 (\% predicted) was $66.7 \%$ (standard deviation [SD] $=22.4 \%$ ) and the mean reversibility was $8.4 \%$, with 49 (18.6\%) patients having a positive bronchodilator test. Up to $39.8 \%$ of the patients had a post-bronchodilator FEV1/FVC ratio above 0.7 , and $40 \%$ had moderate-severe airflow obstruction according to the GOLD severity classification. Mean (SD) Charlson Index was 2.1 (SD = 1.5).

Patients diagnosed with asthma according to physicians criteria had significantly fewer comorbidities $\left(\chi^{2}\right.$ test $P<0.05)$. The EuroQoL-5D questionnaire showed significant differences between the three groups in terms of mobility, self-care, and pain. However, EuroQoL-5D visual analogue scale results showed no statistically significant differences. Most of the patients had dyspnoea grades 2 (45\%) and $3(25 \%)$, with significant differences in the degree of disability between the three groups. As per protocol requirement, all participants were receiving inhaled medication: $230(71 \%)$ were on treatment with any kind of ICs, of these 150 (65.2\%) received a fixed combination with $L A B A s$ (Table 2).

\section{Diagnostic accuracy}

A total of $182(59.3 \%)$ patients fulfilled the GOLD criteria for COPD lpostbronchodilator FEV1/FVC <0.7). As a result of post-bronchodilator spirometry, patients were placed into one of five mutually exclusive diagnostic categories (Table 1); the most frequent was COPD without reversible component $(49.6 \%)$ and up to $9.8 \%$ were classified as probably normal (Table 3 ). The two differential diagnosis questionnaires provided similar percentages of patients with probable COPD $162.8 \%$ with the Tinkelman et al and $58.4 \%$ with the Beeh et al questionnaire). However, the Beeh et al questionnaire classified $41.6 \%$ of patients as probable asthma, whereas the Tinkelman et al questionnaire, focused on COPD, classified $22.4 \%$ as indeterminate probability of COPD, and $14.8 \%$ as reduced probability of COPD (Table 3).

The analysis of concordance showed different levels of concordance between the diagnostic methods (Table 4): concordance was moderate between the clinical diagnosis and spirometry and between the two questionnaires; it was low between the physicians' criteria and the two questionnaires and very low in the other two comparisons: spirometry versus the Tinkelman et al questionnaire and spirometry versus the Beeh et al questionnaire. Global concordance between diagnosis is shown in Table 5.

\section{Use of inhaled corticosteroids}

The use of inhaled medication by clinical diagnosis is shown in Table 2. ICs were the most frequent medication $(71.9 \%)$, being administered in fixed combinations with 
Table 2. Characteristics of eligible patients classified according to physican criteria

\begin{tabular}{|c|c|c|c|c|}
\hline & $\begin{array}{c}\text { All } \\
n=324\end{array}$ & $\begin{array}{c}\text { COPD } \\
n=210\end{array}$ & $\begin{array}{c}\text { Asthma } \\
n=50\end{array}$ & $\begin{array}{c}\text { Indeterminate } \\
n=64\end{array}$ \\
\hline Mean age, years (SD)a & $66.9(11.2)$ & $68.9(9.7)$ & $58.9(13.1)$ & $67.2(11.2)$ \\
\hline Sex, male, $n(\%)^{\text {a }}$ & $204(63.8)$ & $161(77.4)$ & $13(26.0)$ & $30(48.4)$ \\
\hline Mean BMI, kg/m²(SD) & $27.5(4.8)$ & $27.3(4.1)$ & $27.4(6.1)$ & $28.0(5.8)$ \\
\hline \multicolumn{5}{|l|}{ Educational level, $n(\%)$} \\
\hline No studies & $54(17.0)$ & $34(16.5)$ & $4(8.3)$ & $16(25.4)$ \\
\hline Elementary & $110(34.7)$ & 75 (36.4) & 18 (37.5) & 17 (27) \\
\hline High school & $82(25.9)$ & $51(24.8)$ & 15 (31.3) & $16(25.4)$ \\
\hline University & $59(18.6)$ & $36(17.5)$ & $11(22.9)$ & $12(19)$ \\
\hline Others & $12(3.8)$ & $10(4.9)$ & $0(0.0)$ & $2(3.2)$ \\
\hline \multicolumn{5}{|l|}{ Smoking history, $n(\%)$} \\
\hline Active smokera & $76(24.4)$ & $55(27.5)$ & $6(12.8)$ & $15(23.4)$ \\
\hline Ex-smoker & $163(52.4)$ & $120(60)$ & $14(29.8)$ & 29 (45.3) \\
\hline Non-smoker & $72(23.2)$ & $25(12.5)$ & $27(57.4)$ & 20 (31.3) \\
\hline $\begin{array}{l}\text { Mean age at onset, } \\
\text { years (SD) }\end{array}$ & $43.5(21.1)$ & 46.5 (20.3) & 34 (18) & $41.4(23.9)$ \\
\hline Chronic cough, a $n(\%)$ & 227 (71.4) & $156(76.1)$ & 33 (67.3) & 38 (59.4) \\
\hline \multicolumn{5}{|l|}{ Spirometry, mean (SD) } \\
\hline \multicolumn{5}{|l|}{ Pre-bronchodilator } \\
\hline $\mathrm{FVC}, \mathrm{ml}$ & 2744 (892) & $2737.6(884.7)$ & $2748.7(976.5)$ & $2759.8(866.0)$ \\
\hline FVC, \% & $70.1(20.1)$ & $66.9(19.2)$ & 79.2 (20.5) & $73.2(20)$ \\
\hline FEV1, mla & $1753(724)$ & $1635.5(701.2)$ & 1950.2 (713.0) & $1969.4(730.2)$ \\
\hline FEV1, \%a & 64.5 (23.3) & $58.5(21.4)$ & 78.1 (20.3) & 73 (24.3) \\
\hline FEV1/FVC (\%) & $63.9(14.1)$ & $59.9(14)$ & $71.2(9.8)$ & 71.1 (12.3) \\
\hline \multicolumn{5}{|l|}{ Post-bronchodilator } \\
\hline $\mathrm{FVC}, \mathrm{ml}$ & 2826 (930) & 2847.9 (885.9) & 2743.7 (994.3) & $2820.9(1.023 .1)$ \\
\hline FVC, \% & $73.7(17.9)$ & 71.2 (18.3) & $82.4(14.7)$ & $75.2(16.8)$ \\
\hline FEV1, mla & $1856(802)$ & $1724.6(707.4)$ & 2057.5 (778.4) & 2103.0 (989.8) \\
\hline FEV1, \%a & $66.7(22.4)$ & $61.3(21.8)$ & 80.5 (18.2) & $73.7(21)$ \\
\hline FEV1/FVC, \%a & $64.9(15.1)$ & $60.2(14.8)$ & $74.4(10.8)$ & $72.2(12)$ \\
\hline \multicolumn{5}{|l|}{ Reversibility } \\
\hline Percentage & $8.4(11.6)$ & $8(10)$ & $10.6(9.4)$ & 8 (16.5) \\
\hline Positive BDT, a,b $n(\%)$ & $49(18.6)$ & $26(15.6)$ & 15 (37.5) & 8 (14.3) \\
\hline Mean Charlson score I & Ja 2.1 (1.5) & $2.2(1.5)$ & $1.9(1.6)$ & $1.9(1.5)$ \\
\hline \multicolumn{5}{|l|}{ Mean EuroQoL-5D (SD) } \\
\hline EQ-5D index & $0.76(0.20)$ & $0.75(0.21)$ & $0.78(0.22)$ & $0.79(0.17)$ \\
\hline EQ-5D VAS & $61.2(15.4)$ & $60.1(15)$ & $64.2(17.6)$ & $62.5(14.7)$ \\
\hline \multicolumn{5}{|c|}{ MRC dyspnoea scale, $n(\%)$} \\
\hline Grade 1 & $62(19.4)$ & $26(12.5)$ & $22(44.0)$ & $14(22.6)$ \\
\hline Grade 2 & 145 (45.3) & $99(47.6)$ & 19 (38.0) & $27(43.5)$ \\
\hline Grade 3 & $81(25.3)$ & $56(26.9)$ & $7(14.0)$ & $18(29.0)$ \\
\hline Grade 4 & $26(8.1)$ & $23(11.1)$ & $0(0.0)$ & $3(4.8)$ \\
\hline Grade 5 & $6(1.9)$ & $4(1.9)$ & $2(4.0)$ & $0(0.0)$ \\
\hline \multicolumn{5}{|l|}{ Treatment, $n(\%)$} \\
\hline SABA & 179 (55.3) & $110(50.4)$ & $33(66)$ & 36 (56.3) \\
\hline Ipratropiuma & 40 (12.3) & 28 (13.3) & $1(2.0)$ & $11(17.2)$ \\
\hline Tiotropiuma & $148(45.7)$ & $122(58.1)$ & $4(8)$ & $22(34.4)$ \\
\hline ICs with LABA & $150(46.3)$ & $99(47.1)$ & $25(50.0)$ & $26(40.6)$ \\
\hline ICs with no LABA ${ }^{a}$ & $83(25.6)$ & 51 (24.3) & 19 (38) & $10(15.6)$ \\
\hline LABA with no ICs & $31(9.5)$ & 25 (11.9) & $1(2)$ & $5(7.8)$ \\
\hline
\end{tabular}

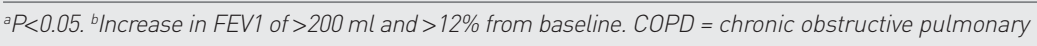
disease. $B D T=$ bronchodilator test. $B M I=$ body mass index. $F E V 1=$ forced expiratory volume in 1 second. $F V C=$ forced vital capacity. $I C=$ inhaled corticosteroids. $\angle A B A=$ long-acting beta agonist. $M R C=$ Medical Research Council. $S A B A=$ short-acting beta agonist. $S D=$ standard deviation. VAS = visual analogue scale

LABAs in most cases. ICs were used more frequently by asthma patients while tiotropium was more frequently used by patients with COPD. A total of $150(71.4 \%)$ patients with a clinical diagnosis of COPD were treated with ICs Imean FEV1 [\% predicted] $61.3 \%$ ), whereas $12 \%$ of patients with the diagnosis of asthma were not receiving ICs. Only one patient diagnosed with asthma was treated with a $L A B A$ alone.

On comparing the use of ICs with the patient characteristics, no significant differences were found between IC consumers and non-consumers in terms of age, sex, age at onset, comorbidity, or quality of life. Educational level appeared to have some influence on use of ICs as the percentage of patient not receiving ICs was higher in high school and university patients compared with patients with a lower educational level. Patients treated with ICs were more severe, both in terms of FEV1 $1 \%$ predicted) and EuroQoL-5D scores ( $P<0.05$ for both comparisons).

Regarding smoking history, there were more active smokers in the non-ICs group (34.1\%) than in the ICs group $120.5 \%$; $P<0.05$; Table 6).

\section{DISCUSSION}

Primary care physicians have difficulties in diagnosing up to $19.8 \%$ of patients with chronic respiratory symptoms taking inhaled medication based on clinical presentation and spirometry. This lack of diagnostic accuracy is, in part, responsible for inadequate pharmacological treatment with overuse of ICs in COPD and underuse in asthma. The use of differential diagnosis questionnaires provides little additional information to spirometry with bronchodilator test, and concordance between the different questionnaires and symptoms and spirometry for the differential diagnosis of COPD and asthma is weak.

Asthma and COPD are not always easy to differentiate. However, the current results have shown that most patients can easily be classified by primary care physicians into asthma or COPD groups based on clinical and spirometric findings, but there are difficulties in classifying up to $19.8 \%$ of patients with obstructive respiratory symptoms. Some patients may share characteristics of both asthma and COPD, which has been called the 'overlap' syndrome. ${ }^{22-24}$ Nevertheless, in most cases both diseases have distinctive aspects that result in different patterns of treatment. The current results indicate that the existing questionnaires of differential diagnosis have poor concordance and, with the lack of a gold standard, they do not offer a great advantage over clinical judgment complemented with the results of a spirometry with bronchodilator test.

Due to the lack of a real gold standard, 


\section{Table 3. Distribution of patients by study method}

\begin{tabular}{|c|c|}
\hline & $n(\%)$ \\
\hline Diferential diagnosis according to spirometry ${ }^{18}$ & $n=266$ \\
\hline COPD without reversible component & $132(49.6)$ \\
\hline COPD with reversible component & 28 (10.5) \\
\hline Asthma & $21(7.9)$ \\
\hline Probable asthma & $59(22.2)$ \\
\hline Probably normal & $26(9.8)$ \\
\hline Differential diagnosis questionnaire (Tinkelman et $a l^{10}$ ) & $n=250$ \\
\hline Increased probability of COPD & $157(62.8)$ \\
\hline Reduced probability of COPD & $37(14.8)$ \\
\hline Indeterminate probability of COPD & $56(22.4)$ \\
\hline Differential diagnosis questionnaire (Beeh et $a l^{16}$ ) & $n=250$ \\
\hline Probable COPD & $146(58.4)$ \\
\hline Asthma & $104(41.6)$ \\
\hline
\end{tabular}

\section{Table 4. Chronic obstructive pulmonary disease (COPD) diagnosis} paired by the four methods used in the study

\begin{tabular}{|c|c|c|c|c|}
\hline \multirow{10}{*}{ 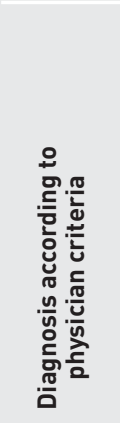 } & & \multicolumn{2}{|c|}{ Diagnosis according to spirometry, $n(\%)$} & \multirow[t]{2}{*}{ Kappa (Cl 95\%) } \\
\hline & & COPD No & COPD Yes & \\
\hline & COPD No & $64(24.1)$ & $32(12.0)$ & $\begin{array}{c}0.4103 \\
(0.2981 \text { to } 0.5226)\end{array}$ \\
\hline & COPD Yes & $42(15.8)$ & $128(48.1)$ & \\
\hline & \multicolumn{4}{|c|}{ Diagnosis according to Tinkelman et al questionnaire } \\
\hline & & COPD No & COPD Yes & \\
\hline & COPD No & $57(22.8)$ & $35(14.0)$ & $\begin{array}{c}0.3908 \\
(0.2731 \text { to } 0.5086)\end{array}$ \\
\hline & COPD Yes & $36(14.4)$ & $122(48.8)$ & \\
\hline & \multicolumn{4}{|c|}{ Diagnosis according to Beeh et al questionnaire } \\
\hline & & COPD No & COPD Yes & \\
\hline \multirow{10}{*}{ 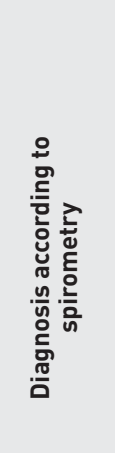 } & COPD No & $57(22.8)$ & 35 (14.0) & $\begin{array}{c}0.3136 \\
(0.1943 \text { to } 0.4329)\end{array}$ \\
\hline & COPD Yes & $47(18.8)$ & $111(44.4)$ & \\
\hline & \multicolumn{4}{|c|}{ Diagnosis according to Tinkelman et al questionnaire } \\
\hline & & COPD No & COPD Yes & \\
\hline & COPD No & 40 (19.3) & $45(21.6)$ & $\begin{array}{c}0.1637 \\
(0.0283 \text { to } 0.2991)\end{array}$ \\
\hline & COPD Yes & 38 (18.3) & 85 (40.9) & \\
\hline & \multicolumn{4}{|c|}{ Diagnosis according to Beeh et al questionnaire } \\
\hline & & COPD No & COPD Yes & \\
\hline & COPD No & $46(22.1)$ & $39(18.8)$ & $\begin{array}{c}0.1986 \\
(0.0644 \text { to } 0.3329)\end{array}$ \\
\hline & COPD Yes & $42(20.2)$ & $81(38.9)$ & \\
\hline \multirow{4}{*}{ 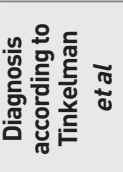 } & \multicolumn{4}{|c|}{ Diagnosis according to Beeh et al questionnaire } \\
\hline & & COPD No & COPD Yes & \\
\hline & COPD No & $66(26.4)$ & $27(10.8)$ & $\begin{array}{c}0.4566 \\
(0.3444 \text { to } 0.5688)\end{array}$ \\
\hline & COPD Yes & $38(15.2)$ & $119(47.6)$ & \\
\hline
\end{tabular}

Table 5. Concordance between the four methods of diagnosis $(n=324)$

\begin{tabular}{lc}
\hline Agreement between the four methods of COPD diagnosis & $n(\%)$ \\
\hline $\begin{array}{l}\text { Physician diagnosis of COPD, with one or more of the other three } \\
\text { methods diagnosing non-COPD }\end{array}$ & 60 (18.5) \\
\hline Physician diagnosis of non-COPD, with one or more of the other three & \\
methods diagnosing COPD & $64(19.8)$ \\
\hline Agreement between the four methods in the diagnosis of non-COPD & $26(8.0)$ \\
\hline Clinical diagnosis was COPD and FEV1/FVC postbronchodilator was $>0.70$ & $84(25.8)$ \\
\hline COPD = chronic obstructive pulmonary disease. FEV1/FVC = forced expiratory volume in 1 second/forced &
\end{tabular}

this study compared different diagnostic methods based on clinical history lincluding smoking habits), symptoms, and spirometry, knowing that none of these data can be separately considered as definitive. When evaluating the agreement in the diagnosis reached by each method, this study found a moderate concordance between the clinical and spirometric criteria for the diagnosis of COPD, with $72 \%$ agreement $116 \%$ of patients clinically diagnosed with COPD did not fulfill the spirometric criteria, while $12 \%$ of patients with spirometric criteria of COPD were not considered as having COPD according to clinical criteria).

The two differential diagnosis questionnaires also showed moderate concordance between them, with an agreement of $70 \%$. However, the concordance was low between clinical criteria and questionnaires, and very low between spirometry and questionnaires $160 \%$ and $61 \%$ of agreement with Tinkelman et al and Beeh et al questionnaire respectively). This study assessed the usefulness of the two questionnaires as complementary method of diagnosis; in fact, neither questionnaire was designed as a diagnostic methods but rather to facilitate the differentiation of asthma and COPD once a chronic obstructive airway disease had been diagnosed. ${ }^{11,1}$

In their study, Beeh and colleagues ${ }^{17}$ concluded that, by means of their questionnaire, most patients with a suspected or established diagnosis of obstructive airway diseases could be classified in asthmatic or COPD groups. Despite the slight improvement achieved with the addition of spirometry results, these authors recognised that spirometry should be mandatory to support the initial diagnosis of an obstructive airway disease and to guide therapy. On the other hand, Tinkelman and colleagues ${ }^{11}$ found their questionnaire to be useful for patients suspected of having obstructive lung disease or those receiving respiratory medications in the absence of a specific diagnosis, although they did recognise the importance of a more efficient use of spirometry and a enhanced diagnostic accuracy to improve the overall management. On observing the poor concordance shown in the current study it was concluded that the questionnaires are of little help in addition to clinical assessment and spirometry with bronchodilator test for the differential diagnosis between asthma and COPD.

Considering the four methods together, 
Table 6. Characteristics of patients according to treatment with ICs

\begin{tabular}{|c|c|c|}
\hline & Any ICs, $n=230$ & No ICs, $n=94$ \\
\hline Mean age, years (SD) & $66.6(11.5)$ & $67.7(10.6)$ \\
\hline Male sex, $n(\%)$ & $143(63.0)$ & $61(65.6)$ \\
\hline Mean BMI, kg/m² (SD) & $27.7(4.9)$ & $26.9(4.5)$ \\
\hline \multicolumn{3}{|l|}{ Educational level, $n(\%)$} \\
\hline No studies & 45 (19.9) & $9(9.9)$ \\
\hline Elementary & $79(35.0)$ & $31(34.1)$ \\
\hline High school & $54(23.9)$ & $28(30.8)$ \\
\hline University & $38(16.8)$ & $21(23.1)$ \\
\hline Others & $10(4.4)$ & 2 (2.2) \\
\hline \multicolumn{3}{|l|}{ Smoking history, $n(\%)$} \\
\hline Active smokera & 45 (20.5) & $31(34.1)$ \\
\hline Ex-smoker & $118(53.6)$ & $45(49.5)$ \\
\hline Non-smoker & $57(25.9)$ & 15 (16.5) \\
\hline Mean packet/year (SD) & $41.2(29.2)$ & $39.6(25.9)$ \\
\hline Mean age at onset, years (SD) & $42.7(21.1)$ & 45.7 (21.3) \\
\hline Chronic cough, $n(\%)$ & $166(74.1)$ & $61(64.9)$ \\
\hline Expectoration, $n(\%)$ & 150 (66.3) & 60 (63.8) \\
\hline \multicolumn{3}{|l|}{ Spirometry ${ }^{a}$} \\
\hline \multicolumn{3}{|l|}{ Post-bronchodilator } \\
\hline FVC, $\mathrm{mL}^{\mathrm{a}}$ & 2697.9 (857.5) & $3122.1(1,025.7)$ \\
\hline FVC, \% & 73.3 (18.7) & $74.8(16.0)$ \\
\hline FEV1, mLa & $1753.1(744.0)$ & $2099.2(883.4)$ \\
\hline FEV1, \% & $66.0(23.4)$ & $68.5(19.7)$ \\
\hline FEV1/FVC, \% & $64.1(15.8)$ & $66.8(12.9)$ \\
\hline Positive BDT' & $34(18.4)$ & $15(19.2)$ \\
\hline \multicolumn{3}{|l|}{ MRC dyspnoea scale, $n(\%)$} \\
\hline Grade 1 & 43 (18.9) & 19 (20.7) \\
\hline Grade 2 & $102(44.7)$ & $43(46.7)$ \\
\hline Grade 3 & $54(23.7)$ & $27(29.3)$ \\
\hline Grade 4 & $24(10.5)$ & $2(2.2)$ \\
\hline Grade 5 & $5(2.2)$ & $1(1.1)$ \\
\hline Mean Charlson score (SD) & $2.1(1.5)$ & $2.0(1.4)$ \\
\hline \multicolumn{3}{|l|}{ EuroQoL-5D } \\
\hline EQ-5D index & $0.74(0.22)$ & $0.80(0.17)$ \\
\hline EQ-5D VAS a & $59.4(15.1)$ & $65.2(15.3)$ \\
\hline \multicolumn{3}{|c|}{ 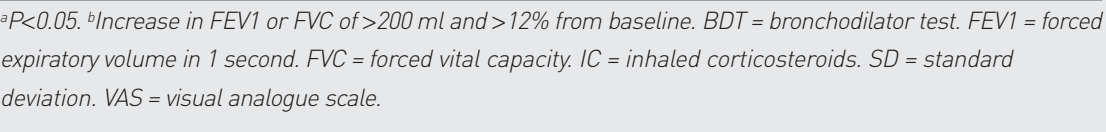 } \\
\hline
\end{tabular}

the concordance was only of $26 \%$, a percentage probably corresponding to patients with a 'pure phenotype'. These results confirm that a significant number of patients with asthma and COPD may share symptoms that may lead to a misdiagnosis between the two conditions. It is known that the overlap of symptoms can complicate a clear distinction between these two diseases, especially in smokers and in older adults. ${ }^{11}$ Age and smoking history are factors that could contribute to the misdiagnosis of COPD in people with asthma.

Although asthma is most often associated with childhood and adolescence, the first manifestation of asthma may also occur in late adulthood. ${ }^{25}$ On the other hand, although smoke exposure is closely related to COPD, up to $30 \%$ of people with asthma are smokers. ${ }^{22}$ Accordingly, the present study found that the mean age at onset was 46.5 and 34 years of age in patients classified as COPD or asthma respectively. In addition, $87.5 \%$ of active or ex-smokers were classified as COPD while only $42.6 \%$ were diagnosed with asthma. These data fit well with the results from a similar study that showed percentages of $85.4 \%$ and $41.7 \%$ respectively. ${ }^{15}$ This lack of concordance illustrates the difficulty of finding a method to achieve a reliable diagnosis, and shows that a high percentage of patients may not present a pure symptomatic frame. In this context, Gibson and Simpson ${ }^{22}$ have defined the overlap syndrome of asthma and COPD as symptoms of increased variability of airflow and incompletely reversible airflow obstruction. Overlap between asthma and COPD can reach $20 \%$ of all patients with chronic respiratory disease. ${ }^{17,26}$ 


\section{Funding}

This project was supported by an unrestricted grant from Boehringer Ingelheim and Pfizer.

\section{Ethical approval}

The study was approved by the Ethics Committee of the Hospital Clinic (Barcelona) and all the participants provided written informed consent (reference 2009/4710).

\section{Provenance}

Freely submitted; externally peer reviewed.

\section{Competing interests}

Marc Miravitlles has conducted the study supported by Boehringer Ingelheim and Pfizer and has received payments for speaking at scientific meetings and participating in advisory boards by the same companies. Esther Anton is a full time employee of Pfizer. The other authors have no conflict of interest to disclose.

\section{Acknowledgements}

The authors wish to acknowledge the following Drs for their contribution to the study: Andreu Altes Boronat, Sonia Rodriguez Martinez (CAP Sants), Isabel Andreu Oliete, Yolanda Romero Fernandez, Marisol de Miguel Baquero (CAP Numancia), Valentin Aragunde Miguens, Nuria Lopez Batet, Sandra Murgui Betran, Francesc Pont Barrio, Anna Peña Sanroma (CAPSE Roselló), Ana Bonillo, Marisa Cabrera Ortega (CAP Magoria), Cristina Calvo Caldentey, Rosa Ma Masso Ubeda, Ana Muñoz Rubio, Tina Navarro Navarro, Jordi Reviriego Chuecos (CAP Manso), Carlos Campmajo Almodovar, Consol Lemonche Aguilera, Carolina Matas Foz, Mireia Pascual Domenech (CAP Adria), Joan Carles Clara Rialp, Sonia Gomez Marti (CAP Montnegre), Marian de la Poza, Bibiana Deixents Martinez (CAP Carles Ribas), Ana Gaspar Lasanta (CAP Consell de Cent), Daniel Geat (CAP Bonaplata), Javier Otero Serra, Salvador Sitjar Marinez (CAP Les Corts). The authors would also like to thank the writing and editing support by Dr Eliana Mesa financed by Pfizer.

\section{Discuss this article}

Contribute and read comments about this article on the Discussion Forum: http://www.rcgp.org.uk/bjgp-discuss
Interestingly, this percentage clearly corresponds with the current finding of $19.8 \%$ of patients clinically classified as 'indeterminate".

Given the different physiopathology of asthma and COPD, both diseases require a different approach to treatment. ICs are considered first-line treatment in asthma but only first-line treatment in patients with severe COPD with frequent exacerbations, and always associated with a long-acting bronchodilator. $3.6,7$

Assuming that the use of ICs may be excessive or inappropriate in COPD, one aim of the study was to ascertain the adequacy of prescription of these agents. The study found that a high percentage of patients clinically diagnosed with COPD were treated with ICs, both in association with LABAs (47.1\%) or alone (24.3\%). Similarly, a high number of patients classified as 'indeterminate' were treated with ICs $140.6 \%$ in association with LABAs and $15.6 \%$ alone). Previous studies have also found ICs among the drugs most frequently used in COPD in primary care, being between $50 \%$ and $75 \%$ of patients according to the different surveys., $827-32 \mathrm{De}$ Miguel Díez et $a^{32}$ found a similar percentage of prescriptions in primary care and by pneumologists $164 \%$ and $60.9 \%$ respectively).

The use of combined therapy could be justified in the case of indeterminate patients, in whom this treatment covers the two processes. However, the authors have no explanation for the use of ICs alone in COPD. On the other hand, the current study showed a considerable number of patients with asthma not receiving ICs (12\%). On analysing the use of ICs taking into account the concordance between the four methods evaluated, it was found that when all coincided in the diagnosis of COPD the percentage of patients on treatment with ICs was of $40 \%$ (in association with LABAs) and $5 \%$ (alone). In contrast, when the four diagnoses were 'non-COPD', the use of ICs with or without LABAs was of 42 and $15 \%$ respectively. This means that ICs may be over-used in the case of COPD and underused when the diagnosis is non-COPD.

In conclusion, in many cases it may be difficult to reach a proper diagnosis of chronic respiratory diseases such as COPD and asthma. The overlapping of symptoms, the lack of a gold standard, and the existence of confounding factors, such as the degree of reversibility in airflow, older age, and smoking habits, contribute to misdiagnosis of these conditions. With the combined use of four methods this study found a substantial non-concordance in the diagnosis in patients attending primary care. From a clinical point of view, the differential diagnosis between the two diseases is important, as the therapeutic approach is different. Apart from patients with a non-accurate diagnosis, this study also detected inadequate use of ICs even in patients correctly diagnosed. This suggests that, in spite of the number of guidelines available for the diagnosis and treatment of respiratory diseases, these are not sufficiently implemented in the primary care setting. 


\section{REFERENCES}

1. Miravitlles M, Soriano JB, García-Río F, et al. Prevalence of COPD in Spain: impact of undiagnosed COPD on quality of life and daily life activities. Thorax 2009; 64(10): 863-868

2. Tinkelman DG, Price DB, Nordyke RJ, Halbert RJ. Misdiagnosis of COPD and asthma in primary care patients 40 years of age and over. J Asthma 2006: 43(1): 75-80.

3. Global Initiative for Chronic Obstructive Lung Disease (GOLD). Global strategy for diagnosis, management, and prevention of COPD.

http://www.goldcopd.org/uploads/users/files/GOLD Report_2011Dec30.pdf laccessed 9 Jan 2012)

4. Global Initiative for Asthma (GINA). GINA report: global strategy for asthma management and prevention.

http://www.ginasthma.org/uploads/users/files/GINA_Report_2011.pdf laccessed 9 Jan 2012)

5. Flor-Escriche X, Rodríguez-Mas M, Espiau M, et al. Compliance with guidelines in the treatment of asthma exacerbations in primary care. Ther Adv Respir Dis 2011; 5(6): 369-375.

6. van Schayck CP, Levy ML, Stephenson P, Sheikh A. The IPCRG Guidelines: developing guidelines for managing chronic respiratory diseases in primary care. Prim Care Respir J 2006; 15(1): 1-4.

7. Peces-Barba G, Barberà JA, Agustí A, et al. [Diagnosis and management of chronic obstructive pulmonary disease: joint guidelines of the Spanish Society of Pulmonology and Thoracic Surgery (SEPAR) and the Latin American Thoracic Society (ALAT)]. Arch Bronconeumol 2008; 44(5): 271-281.

8. Miravitlles M, de la Roza C, Naberan K, et al. Use of spirometry and patterns of prescribing in COPD in primary care. Respir Med 2007; 101(8): 1753-1760.

9. Naberan K, De la Roza C, Lamban M, et al. [Use of spirometry in the diagnosis and treatment of chronic obstructive pulmonary disease in primary care]. Arch Bronconeumol 2006; 42(12): 638-644.

10. Halpin DM, O'Reilly JF, Connellan S, et al. Confidence and understanding among general practitioners and practice nurses in the UK about diagnosis and management of COPD. Respir Med 2007; 101(11): 2378-2385.

11. Tinkelman DG, Price DB, Nordyke RJ, et al. Symptom-based questionnaire for differentiating COPD and asthma. Respiration 2006; 73(3): 296-305.

12. Ernst $P$, Gonzalez AV, Brassard P, Suissa S. Inhaled corticosteroid use in chronic obstructive pulmonary disease and the risk of hospitalization for pneumonia. Am J Respir Crit Care Med 2007; 176(2): 162-166.

13. Crim C, Calverley PM, Anderson JA, et al. Pneumonia risk in COPD patients receiving inhaled corticosteroids alone or in combination: TORCH study results. Eur Respir J 2009; 34(3): 641-647.

14. Drummond MB, Dasenbrook EC, Pitz MW, et al. Inhaled corticosteroids in patients with stable chronic obstructive pulmonary disease: a systematic review and meta-analysis. JAMA 2008; 300(20): 2407-2416.

15. Izquierdo JL, Martín A, de Lucas $P$, et al. Misdiagnosis of patients receiving inhaled therapies in primary care. Int J Chron Obstruct Pulmon Dis 2010; 5: 241-249
16. No authors listed. Standardization of spirometry, 1994 update. Am J Respir Crit Care Med 1995; 152(3): 1107-1136.

7. Beeh KM, Kornmann O, Beier J, et al. Clinical application of a simple questionnaire for the differentiation of asthma and chronic obstructive pulmonary disease. Respir Med 2004; 98(7): 591-597.

18. Charlson ME, Pompei P, Ales KL, MacKenzie CR. A new method of classifying prognostic comorbidity in longitudinal studies: development and validation. J Chronic Dis 1987; 40(5): 373-383.

19. Badia X, Roset M, Montserrat S, et al. [The Spanish version of EuroQol: a description and its applications. European Quality of Life scale]. Med Clin (Barc) 1999; 112 (Suppl 1): 79-85.

20. Bestall JC, Paul EA, Garrod R, et al. Usefulness of the Medical Research Council (MRC) dyspnoea scale as a measure of disability in patients with chronic obstructive pulmonary disease. Thorax 1999; 54(7): 581-586.

21. Price DB, Tinkelman DG, Halbert RJ, et al. Symptom-based questionnaire for identifying COPD in smokers. Respiration 2006; 73(3): 285-295.

22. Gibson PG, Simpson JL. The overlap syndrome of asthma and COPD: what are its features and how important is it? Thorax 2009; 64(8): 728-735.

23. Hardin M, Silverman EK, Barr RG, et al. The clinical features of the overlap between COPD and asthma. Respir Res 2011; 12: 127.

24. Miravitles M. The overlap syndrome between asthma and COPD: implications for management. Hot Topics Respir Dis 2011: 16: 15-20.

25. Bellia V, Battaglia S, Catalano F, et al. Aging and disability affect misdiagnosis of COPD in elderly asthmatics: the SARA study. Chest 2003; 123(4): 1066-1072.

26. Soriano JB, Davis KJ, Coleman B, et al. The proportional Venn diagram of obstructive lung disease: two approximations from the United States and the United Kingdom. Chest 2003; 124(2): 474-481.

27. Miravitlles M, Murio C, Guerrero T, Segú JL. [Treatment of chronic bronchitis and chronic pulmonary obstructive disease in primary care]. Arch Bronconeumol 1999; 35(4): 173-178.

28. Miravitlles M, Calle M, Alvarez-Gutierrez F, et al. Exacerbations, hospital admissions and impaired health status in chronic obstructive pulmonary disease. Qual Life Res 2006; 15(3): 471-480.

29. Llor C, Naberan K, Cots JM, et al. [Risk factors for increased cost of exacerbations of chronic bronchitis and chronic obstructive pulmonary disease]. Arch Bronconeumol 2006; 42(4): 175-182

30. Monteagudo M, Rodriguez-Blanco T, Parcet J, et al. Variability in the performing of spirometry and its consequences in the treatment of COPD in primary care. Arch Bronconeumol 2011; 47(5): 226-233.

31. Izquierdo Alonso JL, Rodríguez González-Moro JM, de Lucas Ramos P, et al. [Has the treatment of COPD changed in Spain? Results of a community multicenter study (VICE)]. Rev Clin Esp 2008; 208(1): 18-25.

32. de Miguel Díez J, Izquierdo Alonso JL, Rodríguez González-Moro JM, et al. [Drug treatment of chronic obstructive pulmonary disease on two levels of patient care: degree of compliance with recommended protocols]. Arch Bronconeumol 2003; 39(5): 195-202. 